\title{
The Effect of Using Mastery Learning Strategy on the Level of Technical and Quantitative Performance of Long jumping skill for Beginners \\ *Dr / Nashwa Ahmed El-Sayed Kamel
}

\section{Introduction and problem:}

\section{Mastery learning}

strategy is a teaching method which depends on providing the learner with several educational alternatives and giving him enough time so that the educational process could realize the desired objectives by allowing the majority of learners to learn and master the provided educational material. It also allows the learner to have the time he needs to absorb a certain subject, in addition to following adequate learning methods that allows the learner to reach mastery level.

Tawfeek Ahmed Meray and Mohamed Mahmoud ElHeela (2007) defines mastery learning as "a set of various educational ideas and practices and a collection of teaching and assessment methods that aims at improving the education provided to learners in order to allow all or the majority of them to reach a level of mastery of the educational material. They also indicate that mastery learning requires the use of small educational modules organized in a consecutive order with specific goals andthrough different levels of performance, initial collective teaching, formative and composite tests as well as individual and collective corrections."

Arlin (2006) states that the best way of learning can be achieved through direct sensory experiences with which students can interact directly. However, in some educational situations this level of interactionbetween the teacher and the student can't be achieved. So, there's a crucial need to look for alternative methods and means for such situations that would, in the same time, help the teacher in transmitting the information to

* Lecturer at the Department of Track and Field Events Faculty of Physical Education for Girls - Zagazig University. 
the students in a better and easier way that can help in achieving the educational goalsexactly like direct experience. This alternative is what we call (educational technologies) that the teacher has to use in his teaching process. Educational experts has deduced that the more we involve several senses in the study of a certain idea, the faster this idea will be learnt and the more experience we will gain. Using adequate situation-based educational technologies during the study is very crucial in the transmission of knowledge to the bigger possible number of students.

Bashir Abdulrahim ElKoloub (2005) defines educational technologies as "technical materials and tools compatible with different educational situations that the teacher uses skillfully and experimentally in the improvement of learning and teaching processes. It also helps in the transmission of senses, clarification of ideas, confirmation of the perception process, increasing the learners' skills and experiences and developing their trends in an interesting atmosphere with a true desire to know better.

Long jumping skill includes four complementary overlapped stages: Approach, Take off, Flight and Landing. Approach and Take off are the most important stages thataffect the distance jumped. Gunter (1999), Steve Rubin (2000), Qasim Hassan and Eman Shaker (2005) indicate that approach in long jump is the biggest challenge for the trainer and the jumper whether in terms of the speed which should be ideal so that the jumper could reach the stage of take off at the highest possible horizontal velocity all while keeping an adequate body posture and respecting take off requirements. On the other hand, high accuracyis required so that the jumper wouldn't, as much as possible, be losing any distance, even small, on the take off board and without any failed attempts.

Given the importance of mastery learning strategy in the mastery of the performance of different motor skills, many scientific studies were conducted by: Martinez \& Joseph (1999), Jorman, et, al (2004), Ali Mustafa Ali (2010), 
Abdulhalim Hafez Yasseen (2012), Sara Mohamed Magdy (2013), El-Sayed Hashim Ahmed (2014), Salah Shaban Ali (2014),Nashwan Mahmoud Daoud, Raed AbdelSattarYounes (2014), Samar Mohamed Mohamed (2015). The results of these studiesindicatethat mastery learning strategy is more effective than command teaching style in the learning and mastery of many motor skills. The researcher has also noticed that there are no studies - to the researcher's best knowledge - that adopted mastery learning strategy in the learning and mastery of long jumping skill for higher education students.

While teaching the curriculum of track and field events at the Faculty of Physical Education for Girls Zagazig University and during her participation in the practical tests at the department, the researcher has also noticed that the first-year undergraduate students of the faculty find it difficult to perform long jumping skill with its different technical stages in spite of the high focus and high attention given to the teaching of the skill. She has also noticed that the student's level of skill performance lacks some techniques of correct performance and that the adopted teaching style does not take into account the individual differences between the students due to the lack of time in the lectures systems and the high number of students in the lecture which resulted in a low motivation to learn. All thisdrove the researcher to attempt to identify and get over such difficulties by using mastery learning strategy which comprises several educational alternatives such as (the teacher - serial illustrations - computer) so that the student could use these educational alternatives during the lecture in order to be able to perform and master the long jumping.

The researcher has found it crucial to benefit from modern teaching methods with its high potentials in the designing and execution of educational programs during the practical lessons of the curriculum of track and field at the faculty. This can be achievedthrougha structured methodological 
frameworkusing mastery learning strategy, which would help in individualizing the learning process and offering it in a good way in order to achieve mastery.

Based on the foregoing, the problem of this research consists in our attempt to identify the effect of using mastery learning strategy, as a modern teaching method, on the level of technical and quantitative performance of long jumping skill among the first-year undergraduate students of the Faculty of Physical Education for Girl at Zagazig University.

\section{Research goals:}

This research aims at identifying the effect of using mastery learning strategy on the level of technical and quantitative performance of long jumping skill for the firstyear undergraduate students at the Faculty of Physical Education for Girls, Zagazig University, and this through the following sub-goals:

1- Identifying the effect of using mastery learning strategy on the level of technical and quantitative performance of long jumping skill.
2- Identifying the effectiveness of using mastery learning strategy and command teaching on the level of technical and quantitative performance of long jumping skill.

\section{Research hypotheses}

1- There are statistically significant differences between the pre and post tests of the experimental group in terms of the technical and quantitative performance of long jumping skill in favor of the posttest.

2- There are statistically significant differences between the pre and post tests of the control group (command teaching style) in terms of the level of technical and quantitative performance of long jumping skill in favor of the posttest.

3- There are statistically significant differences between the posttests of the experimental and the control group in terms of the level of technical and quantitative performance in long jumping skill in favor of the experimental group.

\section{Methodology:}

The researcher adopted the empirical method seen that it fits the nature of this 
research, and this by following the experimental design of two groups;an experimental group and a control group,using pre and post tests.

\section{Population and sample}

By means of the purposive sampling, the researcher chose a research sample of (95) first-year undergraduate students at the Faculty of Physical Education for Girls at Zagazig University at the first semester of the academic year 2015/2016,from a total research population of (786) students with a total percentage of $(12.09 \%)$. (32) Students werechosen for the exploratory study and(7) studentswho are enrolled to repeat the course. So, the basic research sample consisted of (56) students who were randomly divided into two equivalent groups: an

\section{Table (1)}

\section{Indication of the differences between the experimental and the} control groups in terms of growth rates (age - height - weight intelligence)

\begin{tabular}{c|c|c|c|c|c|c}
\hline \hline Variables & \multirow{2}{*}{$\begin{array}{c}\text { Unit of } \\
\text { measurement }\end{array}$} & \multicolumn{2}{|c|}{$\begin{array}{c}\text { The experimental } \\
\text { group N=28 }\end{array}$} & \multicolumn{2}{c|}{$\begin{array}{c}\text { The control group } \\
\mathbf{N = 2 8}\end{array}$} & $\begin{array}{c}\text { T } \\
\text { value }\end{array}$ \\
\cline { 3 - 7 } & & dependent & independent & dependent & independent & \\
\hline \hline Age & Years old & 18.30 & 0.62 & 18.40 & 0.59 & 0.69 \\
\hline Height & $\mathrm{Cm}$ & 165.79 & 4.94 & 166.25 & 5.18 & 0.33 \\
\hline Weight & $\mathrm{Kg}$ & 61.90 & 4.58 & 62.50 & 4.92 & 0.47 \\
\hline $\begin{array}{c}\text { Imagery } \\
\text { intelligence }\end{array}$ & Points & 47.00 & 4.71 & 47.64 & 4.38 & 0.52 \\
\hline \hline
\end{tabular}

$\mathrm{T}$ value is at $0.05=2.031$ significance level

As table (1) shows, there are no statistically significant differences at level 0.05 between the experimental and 
the control group in terms of growth rates under consideration, which indicates that both groups of the research are equivalent in terms of such variables

\section{Table (2)}

Indication of the differences between the experimental and the control groups in terms of the physical variables and the technical and quantitative level of long jumping

\begin{tabular}{|c|c|c|c|c|c|c|}
\hline \multirow[t]{2}{*}{ Variables } & \multirow[t]{2}{*}{$\begin{array}{c}\text { Unit of } \\
\text { measurement }\end{array}$} & \multicolumn{2}{|c|}{$\begin{array}{l}\text { The experimental group } \\
\mathrm{N}=28\end{array}$} & \multicolumn{2}{|c|}{$\begin{array}{c}\text { The control group } \\
\mathrm{N}=28\end{array}$} & \multirow[t]{2}{*}{$\mathrm{T}$ value } \\
\hline & & dependent & independent & dependent & independent & \\
\hline $\begin{array}{l}\text { Muscular } \\
\text { endurance in } \\
\text { legs on the } \\
\text { vertical axis }\end{array}$ & $\mathrm{Cm}$ & 25.19 & 3.24 & 25.35 & 2.39 & 0.18 \\
\hline $\begin{array}{l}\text { Muscular } \\
\text { endurance in } \\
\text { legs on the } \\
\text { horizontal } \\
\text { axis }\end{array}$ & M & 1.37 & 0.15 & 1.40 & 0.18 & 0.66 \\
\hline $\begin{array}{l}\text { Transition } \\
\text { velocity } \\
(30 \mathrm{~m}) \text { with a } \\
\text { crouch start }\end{array}$ & Seconds & 4.77 & 0.24 & 4.72 & 0.29 & 0.68 \\
\hline $\begin{array}{l}\text { Right } \\
\text { hopscotch } \\
\text { with a } \\
\text { standing start }\end{array}$ & M & 0.81 & 0.13 & 0.85 & 0.16 & 0.76 \\
\hline $\begin{array}{l}\text { Left } \\
\text { hopscotch } \\
\text { with a } \\
\text { standing start }\end{array}$ & M & 0.92 & 0.15 & 0.95 & 0.19 & 0.64 \\
\hline $\begin{array}{l}\text { Muscular } \\
\text { strength in the } \\
\text { back }\end{array}$ & $\mathrm{Kg}$ & 47.00 & 3.61 & 47.30 & 2.84 & 0.29 \\
\hline $\begin{array}{l}\text { Flexibility of } \\
\text { the torso and } \\
\text { thighs }\end{array}$ & $\mathrm{Cm}$ & 4.85 & 2.24 & 5.10 & 2.23 & 0.41 \\
\hline $\begin{array}{l}\text { Level of } \\
\text { technical } \\
\text { performance } \\
\text { in long jump }\end{array}$ & Point & 1.00 & 0.50 & 1.11 & 0.55 & 0.77 \\
\hline $\begin{array}{l}\text { Level of } \\
\text { quantitative } \\
\text { performance } \\
\text { in long jump }\end{array}$ & Second & 1.80 & 0.32 & 1.86 & 0.36 & 0.65 \\
\hline
\end{tabular}

$\mathrm{T}$ value is at $0.05=2.031$ significance level

As table (2) shows, there are no statistically significant differences at level 0.05 between the experimental and the control group in terms of the physical variables under consideration and the technical and quantitative level of long jumping, which indicates that both groups of the research are equivalent in terms of such variables. 
Data collection tools:

First: Physical tests:

1- Vertical jumptestfrom stability

2- Horizontal jumptest from stability

3- (30m) Run testwith a crouch start

4- Right / left hopscotch test with a standing start

5- Test of the muscular strength of the back

6- Test of twisting the upper torso upward after standing

Second: Evaluation of the level of performance of long jumping skills:

The researcher evaluated the level of performance of long jumping skills using the "jury method", i.e. four jury members and a president with at least 15 year of experience in teaching track in field events. Each one of them gives a mark to the student. Afterwards, the president of the jury deletes the maximum and minimum marks and counts the student's mark depending on the average middle marks. The skill was evaluated by giving a certain mark out of (10) marks distributed as follows: (three marks for the stage of approach
- three marks and half for takeoff - two marks and half for flight - one mark for landing).

Third: Measuring the quantitative level of the long jumping

The quantitative level of the long jumping was measured as per the rules and conditions for long jumping skills out by International Association for Athletic Federations.

Forth: imagery intelligence test, prepared by / Ahmed Zaky Saleh (1989)

The educational plan based on mastery learning strategy: First: Objective of the suggested educational plan:

1- $\quad$ Learning and mastering long jumping skills by the firstyear undergraduate students of the Faculty of Physical Education at Zagazig.

Second: Basis for designing the suggested education plan: 1- Identifying the general goal of the suggested educational plan

2- Identifying the expected goals of the educational program for the students

3- Identifying the lesson's theme, objective and how it 
can attract the students' attention

4- Applying the preperformance test to all students in order to determine their levels in the skill under consideration

5- The content of the educational modules shall challenge the learners' capacities in order to provoke their motivation to learn.

6- Breaking down the content into small educational modules that the students shall master by the end of the educational unit.

7- Taking into account the individual differences between the learners

8- $\quad$ Preparing tests at the end of each educational module in order to identify the achieved level of mastery. The degree of mastery shall be set at $(80 \%)$ or more.

9- Providing reinforcement learningto students who have mastered the performance and identifying the mistakes of those who have failed to reach the level of mastery as well as taking practical measures to treat such weaknesses using corrective alternatives such as (the teacher - serial illustrations - CD - and dedicating extra time to teach them)

Third: educational alternatives in the educational program

1- The teacher and her role in displaying the model skill and providing verbal explanations to correct the learners' technical mistakes

2- Serial illustrations showing the technical stages for the performance of Long jumping skill

3- CD containing the method of performance and progressive trainings for the long jumping

Forth: Content of mastery learning strategy

1- The stages of the technical performance of long jumping skill were analyzed by reviewing a variety of scientific references in track and field events.

2- $\quad$ The mastery learning strategy's content was submitted to (5) experts in track and field events and teaching methods. They approved the validity of the suggested strategy and ruled it applicable.

3- The mastery learning strategy was approved for the teacher. The teacher's role will 
consist in displaying the model of the skill, providing verbal explanations, $\mathrm{CD}$ and serial illustrations showing the educational steps and stages of technical performance as well as progressive trainings of an easy-to-composed order for the performance of long jumping skill.

4- The students of the experimental group who has achieved $80 \%$ of the desired goal were provided with other educational alternatives such as serial illustrations and CD.

5- The students of the experimental group who have achieved $80 \%$ or more of the desired goal were distributed as leaders over the remaining subjects in order to instruct their peers on mastering the performance of the skill under consideration.

Fifth: Schedule of the suggested educational program:

1- Duration of the research experiment shall be (5) weeks 2- Number of educational modules per week shall be two modules

3- Duration of each daily educational module shall be (90) minutes distributed as follows:
- Warm-up and special

physical preparation

minutes

- The main part (30)

minutes

The researcher indicates that the remaining time (45) minutes of the educational modules were dedicated for teaching the remaining skills of the curriculum of track and field events for the first-year undergraduate students of the Faculty.

\section{Pretests:}

The researcher conducted the pretests for the subjects of the experimental and control groups in terms of growth rates, physical variables as well as levels of technical and quantitative performance of long jump during the period from 12/10/2015 till 15/10/2015.

\section{Application of the suggested educational program:}

The content of the suggested educational program was applied on the subjects of the experimental group during the period from $18 / 10 / 2015$ to $21 / 11 / 2015$ for (5) weeks; two modules per week. The duration of each educational module was (45) minutes, while the control group 
adopted the command teaching style.

\section{Posttests:}

The researcher conducted the posttests for the subjects of the experimental and the control groups in terms of the level of technical and quantitative performance of

\section{Table (3)}

Indication of the differences between the pre and post tests of the first experimental group in terms of technical and quantitative performance in long jumping

\begin{tabular}{c|c|c|c|c|c|c}
\hline \hline Variables & \multirow{2}{*}{$\begin{array}{c}\text { Unit of } \\
\text { measurement }\end{array}$} & \multicolumn{2}{|c|}{ Pretest } & \multicolumn{2}{c|}{ Posttest } & $\begin{array}{c}\text { T } \\
\text { value }\end{array}$ \\
\cline { 3 - 7 } & & independent & dependent & independent & dependent & \\
\hline \hline $\begin{array}{c}\text { Level of } \\
\text { technical } \\
\text { performance } \\
\text { of long } \\
\text { jumping }\end{array}$ & Points & 1.00 & 0.50 & 8.32 & 1.29 & $21.4^{*}$ \\
\hline $\begin{array}{c}\text { Level of } \\
\text { quantitative } \\
\text { performance } \\
\text { of long } \\
\text { jumping }\end{array}$ & $\mathrm{M}$ & 1.80 & 0.32 & 3.71 & 0.35 & $69.21^{*}$ \\
\hline \hline
\end{tabular}

$\mathrm{T}$ value is at $0.05=2.052$ significance level

*Statistically significant at 0.05

As table (3) shows, there are statistically significant differences at level 0.05 between the pre and post tests of the experimental group that long jumping during the period from 23/11/2015 till $25 / 11 / 2015$ following the same pretests.

Presentation and discussion of results:

First: presentation of results: orders and conditions of 
Table (4)

Indication of the differences between the pre and post tests of the control group in terms of the level of technical and quantitative performance in long jumping $\mathrm{N}=\mathbf{2 8}$

\begin{tabular}{c|c|c|c|c|c|c}
\hline \hline Variables & \multirow{2}{*}{$\begin{array}{c}\text { Unit of } \\
\text { measurement }\end{array}$} & \multicolumn{2}{|c|}{ Pretest } & \multicolumn{2}{|c|}{ Posttest } & \multirow{2}{*}{\begin{tabular}{c} 
value \\
\cline { 3 - 6 }
\end{tabular}} \\
\cline { 2 - 6 } & independent & dependent & independent & dependent & \\
\hline \hline $\begin{array}{c}\text { Level of } \\
\text { technical } \\
\text { performance } \\
\text { of long } \\
\text { jumping }\end{array}$ & Points & 1.11 & 0.55 & 7.14 & 1.47 & $15.33^{*}$ \\
\hline $\begin{array}{c}\text { Level of } \\
\text { quantitative } \\
\text { performance } \\
\text { of long } \\
\text { jumping }\end{array}$ & $\mathrm{M}$ & 1.86 & 0.36 & 3.15 & 0.31 & $11.97^{*}$ \\
\hline \hline
\end{tabular}

T value is at $0.05=2.052$ significance level

* Statistically significant at 0.05

As table (4) shows, there are statistically significant differences at level 0.05 between the pre and post tests

Table (5)

of the control group in terms of the technical and quantitative performance of Long jumping in favor of the posttest.

Indication of the differences between the posttests of the experimental and the control groups in terms of technical and quantitative performance in long jumping

\begin{tabular}{c|c|c|c|c|c|c}
\hline \hline Variables & \multirow{2}{*}{$\begin{array}{c}\text { Unit of } \\
\text { measurement }\end{array}$} & \multicolumn{2}{|c|}{$\begin{array}{c}\text { The experimental group } \\
\mathbf{N = 2 8}\end{array}$} & \multicolumn{2}{c|}{$\begin{array}{c}\text { The control group } \\
\mathbf{N}=\mathbf{2 8}\end{array}$} & \multirow{2}{*}{$\begin{array}{c}\text { T } \\
\text { value }\end{array}$} \\
\cline { 3 - 6 } & & independent & dependent & independent & dependent & \\
\hline \hline $\begin{array}{c}\text { Level of } \\
\text { technical } \\
\text { performance } \\
\text { of long } \\
\text { jumping }\end{array}$ & Points & 1.11 & 0.55 & 7.14 & 1.47 & $15.33^{*}$ \\
\hline $\begin{array}{c}\text { Level of } \\
\text { quantitative } \\
\text { performance } \\
\text { of long } \\
\text { jumping }\end{array}$ & $\mathrm{M}$ & 1.86 & 0.36 & 3.15 & 0.31 & $11.97^{*}$ \\
\hline \hline
\end{tabular}

T value is at $0.05=2.031$ significance level

*Statistically significant at 0.05

Assiut Journal For Sport Science Arts 
As table (5) shows, there are statistically significant differences at level 0.05 between the post tests of the experimental and the control group in terms of the technical and quantitative performance of Long jumping in favor of the experimental group.

Table (6)

Rates of improvement of the posttest in relation withthe rates of improvement of the pretest of the experimental and control groups in terms of technical and quantitative performance in long jumping

\begin{tabular}{c|l|l|l|l|l|l}
\hline \hline Variables & \multicolumn{2}{|c|}{ The experimental group N=20 } & \multicolumn{3}{c}{ The control group N=20 } \\
\cline { 2 - 7 } & Pretest & Posttest & $\begin{array}{c}\text { Rates of } \\
\text { improvement }\end{array}$ & Pretest & posttest & $\begin{array}{c}\text { Rates of } \\
\text { improvement }\end{array}$ \\
\hline \hline $\begin{array}{c}\text { Level of } \\
\text { technical } \\
\text { performance } \\
\text { of long } \\
\text { jumping }\end{array}$ & 1.00 & 8.32 & $732.00 \%$ & & & \\
\hline $\begin{array}{c}\text { Level of } \\
\text { quantitative } \\
\text { performance } \\
\text { of long } \\
\text { jumping }\end{array}$ & 1.80 & 3.71 & $106.11 \%$ & 1.86 & 3.15 & $69.35 \%$ \\
\hline \hline
\end{tabular}

As table (6) shows there are rates of improvement in the posttest compared to the pretest of the experimental and control groups in terms of the level of technical and quantitative performance of long jumping. The experimental group's rates of improvement reached (106.11\% - 732.00\%), while those of the control group were $(69.35 \%-543.24 \%)$.

Second: Discussion of results: A- Discussion of the first hypothesis's results:
As shown by the results in table (3), there are statistically significant differences at level 0.05 between the pre and post tests of the experimental group that adopted the mastery learning strategy in terms of the level of technical and quantitative performance of long jumping in favor of the posttest.

Foot plant before takeoff:

- Lean in and slightly back 
- $\quad$ Hips and shoulders lined up

- Good foot placement

Take off:

- $\quad$ Good free leg swing

- $10 \%$ past vertical

- Right shoulder up

In air

- $\quad$ Right-footed jumpers left knee in up - toe up

Over the bar

- K meets together

- $\quad$ Hips are pressed up

* Clearance

- Accelerate shoulders towards

- Put on back side of bar

- Coaching tips

- Develop last two steps and drive

- Drive opposite knee through the roof

- Stay away from bar

- Attack with the side of the body

- $\quad$ Practice jumping on the basketball court

The researcher attributes such improvement in the level of technical and quantitative performance of Long jumping among the students of the experimental group to the existence of several educational alternatives (the teacher and her role in displaying the practical model and providing a verbal explanationthereof - the CD the serial illustrations) that led to provoking the learner's interest and motivating her to exert efforts without feeling bored. This strategy also helps the learner in learning the skill in accordance with her own rhythm, as well as correcting the technical mistakes of her performance immediately after their emergence. As there's no specific time set for learning, each learner takes his time to learn, receive feedbacks and pass to the next module after mastering $80 \%$ of the educational task. This in turn led the learners to master long jumping skills.

This result is consistent with the results of the following studies: Martinez \&Joseph (1999), Jorman, et, al (2004), Ali Mustafa Ali (2010), Abdulhalim Hafez Yaseen (2012), Sara Mohamed Magdy (2013), El-Sayed Hisham Ahmed (2014), Salah Shaban Ali (2014), Nashwan Mahmoud Daoud, Rayed AbdelsattatYunis (2014), Samar Mohamed Mohamed (2015) on the effectiveness of using mastery learning strategy and its educational alternatives 
(the teacher - CDs Educational videotapes - Serial illustration) in the learning and mastery of motor skills in individual and collective sports.

This result is consistent with Zaky Mohamed Hassan (2002) who has indicated that mastery learning is one of the best modern teaching styles thanks to the features it provides such as displaying the educational material in the form of serial interconnected tasks, creating positive tendencies towards the educational subject as well as diagnosing study problems since the beginning of the educational process and handling such problems before they are aggravated and before it becomes difficult to solve.

Thus, the validity of the research's first hypothesis has been established

As shown by the results in table (4), there are statistically significant differences at level 0.05 between the pre and post tests of the control group in terms of the level of technical and quantitative performance of long jumping in favor of the posttest.
The researcher attributes such improvement in the level of technical and quantitative performance of long jumping among the subjects of the control group to the effectiveness of the use of verbal explanations style and the performance of a practical model (command teaching style) in learning the skill under consideration. This style depends on providing verbal explanations on the performance of the skill being learnt. Afterwards, the teacher performs a model of such skill following progressive educational steps, makes a follow-up of the students' performance and provides them with feedbacks at the same time. This helped the students to easily absorb, understand and learn the skill under consideration.

These results are consistent with Martin \& Lumsden (1997) who note that when the teacher gives the learner a clear idea about the appropriate practical performance, this makes the learner more effective. Also, one of the best skill learning styles is when the teacher shows the skill to the learner 
by providing a good performance example, so that the learner would be able to discover such motor tasks in his own body.

Thus, the validity of the research's second hypothesis has been established

A- Discussion of the results of the third hypothesis:

As shown by the results in table (5), there are statistically significant differences at level 0.05 between the posttests of the control group in terms of the level of technical and quantitative performance of long jumping in favor of the experimental group.

The researcher attributes the mastery of the experimental group over the control group in terms of the level of technical and quantitative performance of Long jumping to the effectiveness of the use of the suggested educational program by the experimental group through mastery learning strategy;a modern teaching method which reinforces the educational process by providing several educational technology alternatives for the transmission of information to the studentswith less time and effort,while getting the highest benefit possible. Mastery learning is based on the breaking down of the motor skill into small part following a logical, organized and consecutive order in the form of static images and animations "videos", a written text and live clips on a CD. This helped the students to concentrate on, understand and easily learn the whole part and, afterwards, to be able to perform the skill under consideration.

This result is consistent with the results of the following studies: Martinez \& Joseph (1999), Jorman, et, al (2004), Ali Mustafa Ali (2010), Abdulhalim Hafez Yaseen (2012), Sara Mohamed Magdy (2013), El-Sayed Hashim Ahmed (2014), Samar Mohamed Mohamed (20105) on the effectiveness of the use of mastery learning strategy in learning and mastering motor skills in comparison to the traditional method (command teaching).

This result is consistent with Ibrahim Abdulqader (2000), Fadel Khaleel Ibrahim (2002) who has indicated that mastery learning strategy or 
learning till mastering enriches the educational process by breaking down the content of the educational material into small educational parts (frameworks) following a logical order which allows the learners to interact with the unit in accordance with their own abilities and tendencies by taking into account the individual differences between the learners. In addition, this strategy determines the learner's level before and after the educational module, so that the learner could define his actual level and what he has achieved. This makes the learner active and not passive as in the traditional teaching method which is based on indoctrinating and inculcating the learner by his teacher.

As shown by the results in table (6), there are rates of improvement in the posttest in comparison to the pretest of the experimental and control groups in terms of the level of technical and quantitative performance of long jumping. The experimental group's rates of improvement reached (106.11\% - 732.00\%), while those of the control group were $(69.35 \%-543.24 \%)$.
The researcher attributes this improvement to the new educational environment, which was provided for the students of the experimental group, with its visual and sensatory stimulus, written texts and animations showing the ideal performance of long jumping skill by means of computers in addition to serial illustrations. All this leads to a new interaction which instigates scientific and positive thinking and works on adapting the educational process in accordance with each student's desires and rhythm. This made the students feel the importance of their role in the educational process, and accordingly, master the performance of long jumping.

Mohamed Mahmoud El-Heela (2001) adds that it's important to use and apply the master learning strategy in the educational field. This strategy aims at mastering the information and skills to be learned without setting a specific time for learning. Each leaner takes his time to learn and understand the educational material by providing him with several educational alternatives that work on implanting the 
educational material into the learner's mind.

Thus, the validity of the research's first hypothesis has been established

\section{Findings:}

1- The effectiveness of mastery learning strategy in the promotion of the level of technical and quantitative performance of long jumping for the first-year undergraduate students at the Faculty of Physical Education for Girls, Zagazig University.

2- The command teaching style has a positive effect on the level of technical and quantitative performance of long jumping for the first-year undergraduate students at the Faculty of Physical Education for Girls, Zagazig University.

3- Mastery learning strategy has outweighed command teaching style in terms of the posttests and rates of improvement of the posttest over the pretest of the level of technical and quantitative performance of long jumping.

\section{Recommendations:}

1- The necessity of using mastery learning strategy for learning and mastering the performance of Long jumping skill for the first-year undergraduate students at the Faculty of Physical Education for Girls, Zagazig University. 2- Working on the production of several educational alternatives (CDs - educational modules - serial illustrations educational videotapes) for the learning and mastery of long jumping skills for the first-year undergraduate students at the Faculty of Physical Education for Girls, Zagazig University. 3- The importance of adopting teaching styles that give the learner an active role during the educational process in line with educational developments, including mastery learning strategy.

4- Encouraging the teachers at the departments of track and field events at the Faculties of Physical Education to use nontradition teaching styles when teaching the curriculum of track and field events to the students.

\section{References:}

First: Arabic References:

1- Ibrahim Abdulwakeel

El-Far (2000): ComputerBased Learning and Challenges of the $21^{\text {st }}$ Century, Dar Al-Kitab Al-Jamey - AlAin - UAE. 
2- Aboulnaga Ahmed Ezzeddin (2004): Teaching "Methods - Styles Strategies", ShagaratEldor Library, Mansoura.

3- Ahmed Zaky Saleh (1989): Imagery Intelligence and Test Instruction Booklet, El-Nahda El-Arabiya Library, Cairo.

4- Egyptian Athletics Federation (2012): The International Sports law, Cairo. 5- El-Sayed Hashim Ahmed (2014): " Effect of Mastery Learning on the Level of Performance of Some Athletic Events for the Students of the Preparatory Grade at Kuwait", Physical Education Researches Magazine, Vol. (48), Release (94), Part I, Faculty of Physical Education for Boys - Zagazig University.

6- Bastaweesy Ahmed Bastaweesy (1997): Track and Field Events - Teaching Tactic - Training, Dar Al-Fikr Al-Araby - Cairo.

7- Bashir Abdulrahim ElKolob (2005): Communications and Educational Technology, Dar Al-Kalam, Kuwait.

8- Tawfeek Ahmed Mer'y, Mohamed Mahmoud El-Heela (2007): Individualized
Learning, Ed. 3, Dar El-Fikr, Amman.

9- Zaky

Mohamed

Hassan (2002): Methods of Teaching of Volleyball, AlIshaa Library, Alexandria.

10- Saram

Mohamed Magdy (2013): The Effectiveness of Mastery Learning Strategy on the Level of performance of Some Attack Skills in Basketball for the Students of the Faculty of Physical Education", Master Thesis, Faculty of Physical Education - Benha University. 11- Samar Mohamed Mohamed (2015): "The Effect of Mastery Learning Integrated Educational Program on the Level of Star 3 Skills in Swimming", Master Thesis, Faculty of Physical Education for Girls - Zagazig University. 12- Salah Shaaban Ali (2014): "The Effect of an Educational Program Based on Mastery Learning Strategy on the Level of Cognitive Learning and the Level of Performance of Methodological Skills in Volleyball for the Students of the Second Grade of the Basic Learning", Master Thesis, Faculty of Physical Education, Assiut University. 


\section{3- Abdulhalim Hafez} Yaseen (2012): "The Effect of Mastery Learning on the Learning of the Skill of Hitting the Ball in Tennis", Magazine of the Faculty of Physical Education, Vol. (24), R1. (4), Faculty of Physical Education, Baghdad University, Iraq.

\section{4- Abdulhalim}

Mohammed Abdulhalim et al., (2002): Track and Field Events: Theories and Applications, Dar El-Wafaa for Printing and Publishing, Alexandria.

15- Ali Mustafa Ali (2010): "The Effect of Using Mastery Learning Strategy on the Learning of a Set of Free Trainings for the Students of the Department of Training at the Faculty of Physical Education - Tanta University, Master Thesis, Faculty of Physical Education - Tanta University.

16- Fidel Kaleen Ibrahim (2002): Mastery Learning Strategy, Resale Al-Taby, Release No. 1, Ministry of Education, Muscat, Oman.

17- Lassen Has a Hussein, Eman Shaker (2005): Mechanical, Analytical and Technical Basis in Track and

Field Events, Ed., 2, Dar AlFir, Amman, Jordan.

18- Kamala Jam eel EIReedy (1998): Updates of Athletics, Dar El-Maktaba ElWataniya - Cairo.

19- Magdy Aziz Ibrahim (2005): Pedagogical Fundamentals of the Teaching Process, Ed. 4, Anglo Library, Cairo.

20- Mohamed Hassan Allawy, Mohamed Nasr Eddin Radwan (2001): Motor Performance Tests, Ed. 4. Dar Al-Fikr Al-Araby, Cairo.

\section{1- Mohamed}

Sa'dZaghloul, Mustafa ElSayeh (2004): Technology of Preparation and Rehabilitation of the Teacher of Physical Education, Dar El-Wafaa for Printing and Publishing, Alexandria

22- Mohamed Saad Zaghloul, Makram Abou Harga, Hany Abdulmoneim (2001): Educational Technology and its Methods in Phyiscal Education, Al-Kitab Center for Publishing, Cairo.

23- Mohamed

Hassanein

Measurement and Assessement in Physical Education, Ed. 4, Part I, Dar Al-Fikr Al-Araby, Cairo. 
24- Mohamed Mahmoud

El-Heela (2001): Teaching Methods and Strategy, Dar AlKitab Al-Jamiy, Al-Ain, UAE. 25- Mohamed Mustafa Badran, Ibrahim Motawe', Mohamed MohamedAttia (1999): Educational Tools, Dar Al-Maaref, Cairo.

26- Mustafa El-Sayeh (2004): Technological Method, Educational Technology and Education in Physical Education, Dar El-Wafaa for Printing and publishing, $1^{\text {st }}$ Ed., Alexandria.

27- Nashwam Mohamed Daoud, Rayed AbdulsattsrYunis (2014): ":The Effect of Mastery Learning on the Development of Creative Thinking and the Learning and Retention of a Certain Number of Attack Skills in Basketball, Physical Education Sciences Magazine, Vol. (7), Rl. (3).

Second: Foreign References:

28- Arlin, M., (2006): Time, equality and mastery learning, Review of Educational Research, 59, (1984) pp; 55-86.

29- Bonnie, S, et., al., (2002): Teaching Middle School physical Education Human kineties, Unite States
Human Kinetic p. o. Box 506, Champaign.

30- Donal, S., (2006): Teaching by Multimedia as Systems Approach Sport Media, New York.

31- Gunter Tidow (1999):

Models for Teaching Techniques and Assessing Movements in Athletics: The long jump, Journal of Biomechanics, Vol., 32 issue 12, Dec.

32- Jorman, L., (2004): Effect of a Mastery Learning Strategy on Teaching the Basic Skills Basketball, Journal of Educational Research, Vol., 92, No.,5.

33- Martin \& Lumsden (1997): Coaching an Effective Behavioral Approach college publishing, Toronto.

34- Martinez \& Joseph (1999): Effect of a Mastery Learning Strategy on Teaching the Basic Skills Basketball, Journal of Educational Research, Vol., 92, No.,5.

35- Richard \& Jensen (1997): Micro Teaching, Effective Behaviors Educational, Technology, Dec. 36- Steve Rubin (2000): Accuracy in Horizontal Jumps Approach, Track Coach, No., 152. 